\title{
THE LIMITS OF LANGUAGE IN DOING SYSTEMS WORK
}

\author{
Richard J. Boland, Jr. \\ Weatherhead School of Management \\ Case Western Reserve University \\ U.S.A.
}

\begin{abstract}
Doing systems work brings us to the limits of language as few human activities do. It uniquely joins the empathetic reading of human motivations, desires, and needs with a creative envisioning of new socio-technical arrangements in hopes of transforming the world. It is at once humble and audacious, finely detailed and grandly epic. Fundamental notions of goodness, truth, and beauty are relied upon in ways that forever challenge our ability to justify.

This paper sets five voices in dialogue to explore the limits of language in doing system work. The five voices, C. West Churchman, Sir Geoffrey Vickers, Richard Rorty, Bruno Latour, and Pierre Bourdieu, represent a wide range of $20^{\text {th }}$ century traditions in system thinking, philosophy, sociology of technology, and social theory. Their dialogue is animated, conflictual, melodic, and unnerving, much like system work itself. Instead of a consensus on language, limits, or systems, they provide us a landscape and some paths for future exploration in our own dialogues.
\end{abstract}

This is a fictional account of an imaginary, virtual meeting in which the voices of Pierre Bourdieu, C. West Churchman, Sir Geoffrey Vickers, Bruno Latour, and Richard Rorty create a roundtable discussion on the topic "Are there limits to language which affect the design of information systems?" The pretext for this virtual meeting is a funding initiative by the Millennium Technology Committee, an arm of the European Union Millennium Celebration Council, to conduct a series of studies on the current state

The original version of this chapter was revised: The copyright line was incorrect. This has been corrected. The Erratum to this chapter is available at DOI: 10.1007/978-0-387-35505-4_33 
of information technology deployment in industrial society. One of the studies, of which this roundtable is a part, is to revisit the age old questions of system implementation. Why do so many good ideas for information technology go unrealized? Why are so many systems not successfully implemented? Why are systems often not used to their full potential? In this roundtable on the limits of language and the doing of systems work, four of the participants are imagined to be participating in a human form, while Geoffrey Vickers is imagined to be in a cyber form. He is being represented in the roundtable discussion by a conversational system that has been created from Sir Geoffrey's writings and those of his favorite authors.

The format is thus somewhat unusual, but this performative approach to writing was chosen as a way to make the ideas of these authors come alive just a bit more than in a normal paper. Also, it is an attempt to allow ideas to emerge in the process of writing the voices of the paper, allowing each voice to have its way, and see where it leads. The things these characters say are not intended to represent anything their real counterparts, living or dead, actually have said, although they are intended to represent what the characters might have said. So there are no quotations from their writings where these statements are to be found. Rather, this virtual meeting is put forward as a modest attempt by one person, who has spent some time thinking about their individual writings, to set them in conversation and see what happens.

The format is a video conference in which Geoffrey Vickers' synthesized voice is accompanied by animation of him based on a film produced during his presentation at the Second International Symposium on Communication Theory and Research in March, 1966.

Geoffrey Vickers: This workshop was called because you are some of my favorite thinkers on the questions relevant to the design of information technology in organizations. West Churchman was chosen for his work in system thinking and the systems approach to inquiry. Bruno Latour was chosen for his studies of the way we put our interests to work in creating and deploying technologies, the study of how systems come to be as a continuing accomplishment. Pierre Bourdieu was chosen for his unique approach to the study of the social world and the process of generative structuralism that produces and reproduces organizational practices. Richard Rorty was asked to join us because of his beautiful writings as an American pragmatist, in the tradition of Dewey. So you might see that I have chosen this group as a reflection of how I define myself. I am a pragmatist who is focused on practice and recognizes the socially imbued quality of the multivalued judgements we must make in designing and managing organizational systems.

The topic of "The Limits of Language" was proposed because of my own position that the language and cognitive schemas, which we as humans have evolved over the last million years or so, are now encountering a new kind of environment, one of our own making, to be sure, but one in which we are increasingly blinded to the limits of thought and action that we have created for ourselves. The limits of language are thus, in a sense, of our own making in the context of our evolving state of societal development. I would like to start our discussion by exploring those ideas a bit more fully and then open it up to your criticism and your own position on language, limits, and design. But first, I want to thank you all for joining me in this virtual roundtable tonight. 
Pierre Bourdieu: I am willing to participate in this experiment, but I think the questions of organization, computers, and technology that you pose are much more complex than the way you have represented them.

West Churchman: You haven't, for instance, mentioned ethics as an essential feature of any such discussion.

Bruno Latour: I don't know what I can contribute to this complicated topic you have chosen. I know so little about organization, but then none of us does. Still, I will do what I can.

Richard Rorty: Well, I'm looking forward to an interesting evening and will try to help the conversation along.

Geoffrey Vickers: Let me open the discussion by summarizing why I have posed the topic as the "Limits of Language." I don't have a specific limit in mind, but rather a belief that all systems have in them an inherent set of self-generated limits and that those limits are associated with the characteristic dynamics of that system as those dynamics affect its ability to evolve and adapt to changing circumstances. That, of course, is a general system belief, and in a moment I will identify some ways in which I see that systemic principle applying to language. But another reason I choose that title is Wittgenstein's haunting phrase from the Tractatus, "The limits of my language are the limits of my world." That line is so evocative for me, that I find it popping into my thoughts all the time. I was reminded of these lines just recently while reading an interview with Frank Gehry on the expression of ideas in architecture and he said, "You cannot escape your language." So in both those senses, I felt that "Limits of Language" would be an intriguing topic for us.

The systemic limits of language that concern me most are, first, the limits related to the collapse of the multivalued experience of human judgement into a single valued language of policy discourse; and second, the limits resulting from a language that has evolved over many millennia of rather slow change, confronting a world of exceedingly rapid change. Let me discuss each of them briefly. First, we are, I believe, limited in our ability to reason at the policy level because our language confuses questions of value with questions of efficiency. Our language collapses judgements of what we value and of what constitutes a betterment for us given those values, with judgements of what constitutes an expansion of our resources or an increase in efficiency in our use of these resources. Judgements of betterment are political judgements, and judgements of expansion are economic judgements, each having their own language and logic. Yet, we replace a judgement of betterment with a judgement of expansion by allowing an economic language to be the sole language for thinking through organizational and technological design questions. In organization design, we don't use a language of politics to discuss our values and our judgements of betterment, and our organizations are the worse off for it-especially in the uses of technology. 
Pierre Bourdieu: If by your preference for a language of politics you are saying that the field of organization is fundamentally a field of power struggles, then we have a common reference point.

Geoffrey Vickers: I'm not just saying that-I am saying that our language is inadequate to our task as responsible actors in today's social world. Perhaps the best way to map it into your work is to say that our habitus and language practice present us with objectified structures that collapse judgements of betterment into an economic vocabulary of expansion. This fools us into using a trajectory-like image for guiding our thinking about design, management, and organization rather than a more appropriate image of balance. We are dominated by images of directionality, especially upward thrust, rather than images of the give and take in evolutionary adaptation. Our guiding imagery is based on increase and forward motion rather than balance and adjustment.

In this way, our language and its related mental schemata hides from us the systemic properties of self generated limits in social systems and of the need for more cybernetically sensitive vocabularies for use in policy discourse. We go around changing the world to suit ourselves and mistakenly believe that we are expanding our opportunities rather than limiting them. We believe our increasing use of technology is giving us increased power and control. This expectation is part of our habitus from which we cannot easily escape. We don't see that it is really creating new forms of instability in our social systems, and that those instabilities become the source of new problems, which we address with the same misguided logics of expansion and control.

Pierre Bourdieu: I would like to pose right at the beginning that much as I appreciate your use of my ideas and the generative cycle of practices you have just sketched for us, I take the limits of language to be quite different than what you have proposed, especially if we mean to reflect on the practice of system work. If system work means the construction of information technologies in organizations, then I think it is much more appropriate for us to step back from suppositions about language structures and look carefully at the field in which that language operates, especially the struggle for power in that field and the ways in which system work is a structuring structure. By that I mean that we must attend to the ways in which system work is the reproduction of power relations and the redistribution of capital in organizational fields. System work and its use of language has a structure that shapes the ongoing creation of structures. Systems of information technologies then themselves become structuring structures and in so doing they objectify the subjectivity, which you seem to be so fascinated by.

If there is a limit to language, it is found in the ways in which individuals come to believe that their habitus - their orientations, expectancies, and readiness to act - are a universal subjectivity rather than a localized field of practice in which their particular subjectivity is generated. A generative structuralism of binary oppositions that characterizes a domain of action marks positions in their field and determines the forms and distribution of its capital. This is all relational and must be approached as such. In other words, it isn't the logic of the actor, but the logic 
of the practice in a field that is going to generate the objective probabilities of that field that we must consider if we are to explore limits of language in system work.

C. West Churchman: You are at once too close to the ground with your talk of local practice in fields, and too far from the real problem with your talk of structured structuring structures. Yes, we have habitus and fields, or as I prefer to say, "Weltanschauung," but that is a condition for the operation of reason, and it is the operation of reason that we must pay attention to here. If there are limits to language, they will make differences in our choice decisions, or they will make no difference at all. And the central requirement for reason is to have a guarantor. The guarantor of reason in language use will ultimately have to do with finding a way to, as it were, swallow the whole. By this I mean that reasoned choices, to be rational in any meaningful sense, must be choices that consider the full, relevant system and chose from the full set of available alternatives. So it is not just the thing that someone does or chooses to do that determines its rationality; but we must also include a consideration of all the things that they do not do or choose to do. It is the construction of the alternatives that we choose among that we should be paying attention to, if we are serious about the real limits of language. Looking at practices may be of some relevance in the modeling of systems, but it is on the modeling of our world, and of worlds other than ours, that we must focus, not on practice as it is today. Modeling of possible worlds and inquiry into their functioning as wholes is what will enable us to create a more enduring and beautiful world, which is what doing systems work is all about.

Pierre Bourdieu: All the other possible worlds and their alternatives! Worlds other than our own! Such bizarre and uniquely American ideas of "boundless frontiers" and fascination with an expansive destiny. The logic of practice is always very heavily constrained when our habitus, as memory, meets the objectivity of a field. Our history is brought forward into the present in our habitus, and the field we encounter has an objectified structure that we cannot reinvent. The result is an objective set of probabilities for practice, not an open world of "anything goes." It is because we carry the full burden of our past that we experience the limits of language.

Bruno Latour: Excuse me, but if I may sneak a word in edgewise here, I am fascinated and also humbled by the incredibly detailed knowledge and precise expression you two possess about something I find utterly mysterious. The words you have been using with such abandon - words like society, structures, policy, cybernetic systems, and so on-are completely beyond my humble ability to do tricks with and to juggle in the ways that you do. My vocabulary in comparison is quite poor. I don't know how to begin dealing with these invisible things you seem to take for granted. Where can I go and observe them? What door of what room in regular or cyber space should I open so that I can learn to know them in this amazing way?

I know it's tempting to speak of such imaginary things as if they had a certain causal power in your life. These kinds of fetishes can perhaps bring you some piece of mind or at least provide a handy stopping point for your arguments, but they should be resisted if we are to say something interesting about technology and organizing. 
When I told my friend Barbara Czarniawska that I was going to participate in this cyber salad on the limits of language, she immediately exclaimed, "There are no limits to language! We are always saying new things, always inventing new words, creating new forms of expression and new genres!" And, of course, she is right in a certain sense, but I do see even in our little discussion here this evening how particular ways in which the participants use language sets limits for our thinking. Sir Geoffrey, for instance, in his strangely disembodied form, argues that our language tricks us into thinking about trajectories when we really should be thinking about evolutionary adaptability. But either way, whether it is a mythical journey to Nirvana or whether it is sexual reproduction making us ever more fit as a species, you end up fixated on an imaginary essence without realizing how that essence is necessarily tangled up in all manner of mysterious, invisible causal explanations.

Professor Bourdieu, on his part, is limited by the very precision of his language, so that fields, habitus, forms of capital, positions, and power struggles become a landscape from which he cannot escape to simply look around and consider what other things might be going on in creating an organization and its technologies. What a dreary, predetermined world this language of practice becomes. We can use it to explain everything, yet we understand nothing. I realize that Professor Bourdieu is somewhat aware of how our apparatus for viewing the world limits us, and that he asks his devotees to purify their predetermined analysis with reflexivity on their own reflexivity. But these reverberating reflexive shadows will not help their eyesight, and it is a humble, open set of eyes and ears we need in studying system work.

West Churchman wants us to be able to see wholes-but the social world we live in is flat. There is no place one can stand to see wholes or anything like them in this flat world of ours. There are no lumpy, abstract high points in the landscape: a closely limited horizon of local situations is all we have to see and navigate within. So immediately his language limits us to the unseeable, the unspeakable, and the unreachable. This, I hope you will all agree, is a pretty severe limit.

Pierre Bourdieu: Mr. Latour is a bit too flamboyant for my taste and his false modesty of how little we know of organizations is not well founded. I do know something about information technology design and organizations. I believe it would be clear to anyone who takes the trouble to collect and quantify and categorize the data in the exhaustive and careful manner that I have, that we can know certain things about the fields, habitus, and practice involved. The field of the technology analyst is a globalized professional field in which consultant/designers struggle for the cultural capital of intellectual achievement and for economic capital. The field of the worker is, in contrast, a local organizational field in which workers struggle primarily for the social capital of affiliation. From this view, the problem of implementation is readily apparent. The logic of practice of the consultant/designer expects that workers should be readily willing to make some simple change in daily routines because it is a rational response to the functional requirements of accumulating intellectual capital. For the worker, embedded in a generative cycle of social capital based practices, a change that is considered minor by the designer is in fact a threatening disruption of their life and very position in the field. A disruption of the very relations and conditions on which their social capital is based. 
I further know that the consultant/designer and the worker are in fields with different temporal rhythms. For the worker, it is a rhythm of short cycles and many repetitions per day. For the designer, it is a long cycle rhythm with weeks or months between milestones or repetitions. For the worker, it is a rhythm of familiarity; for the designer, a rhythm of novelty. The designer moves freely through a global professional space while the worker is generally confined to a local market of limited movement. And I could go on and on with these things we know quite clearly about information technology and organizations. It is not so mysterious as you claim.

C. West Churchman: I agree with you on that last point, at least. And in my own defense, I know that the designer has to act. As befuddling as the situation might seem, designers have to muster the courage and the moral judgement to model the whole as best they can, recognizing the inferential leaps involved, and deducing a choice. Imperfect as this sounds, and difficult as the limits of language we have all identified make it, the designer has to act and act responsibly. And because I know that, I know that reason as a guarantor for the designer's action is the foundational language problem we must address.

Richard Rorty: And I know that we have a striking diversity of vocabularies here: flatland, generative structuralism, schematas, deductive logics, and all the subtexts they proliferate. There is a peculiar sense in which all of you are using vocabularies that are implicitly claiming to let us hear or see organizations as they really are. Of course, you know I reject that claim, but what are we left with? What kind of conversation do we make with all these vocabularies overturning and undermining each other? I think of Wittgenstein's comment on language from the Philosophical Investigations: "And how many kinds of sentences are there? Countless kinds. Think of the tools in a tool box." I would like us to think of these different vocabularies we have displayed here tonight not as contestants in a competition to see who is right or who is closest to getting the correct description of technology or organization or system work, but as tools available to a discerning crew of workers doing system work. Or perhaps we should think of them as voices in a chorus where the thing we try to get right is the harmonious blending of voices - the aesthetics of representation that we can interweave with these diverse voices. The "cash value" of what we can do with them. And also, how these voices in this chorus can open us to invite other vocabularies of representation including sound, visual imagery, art, and even dance into our conversations.

I like Barbara's strong intuition about the question we are discussing. There are limits to language only if we let there be limits, through shutting off other voices and closing off our conversations, because we fear they might lead to dead ends. But, of course, this leaves us in our self made dead end, conversing only with those who prefer our own preferred vocabulary. Keeping the conversation going with an open and changing chorus of vocabularies is the best way I know of to keep language subject to limits.

Geoffrey Vickers: This notion of music, imagery, and art is one point I strongly agree with. I've always felt there were multiple forms of consciousness at work in the way 
judgements were actually made in organizations. I've always thought that multiple kinds of sensations were involved in what I call appreciate judgements, or the process in which our judgements of reality and our judgements of value are brought together in a multi-valued judgement of fit. We know something is the correct thing to do not because of logic alone, but because of an appreciative judgement of appropriate balance between the multiple values we hold and the reality we face. Appreciative judgement rests on aesthetics and on all the senses, which are subject to aesthetic judgements of fitness, appropriateness, and desirability. Appreciative judgement is what drives action when it is good, true, and beautiful, not rational choice.

Richard Rorty: There you go again, down a path of searching for an ideal manager's own preferred vocabulary.

Bruno Latour: But you know, Richard, as I sit here listening to you, it suddenly hits me how you yourself are trapped in a limited vocabulary of associating thinking with something that happens in our heads and something that takes place in words. I much prefer to think of thinking as something we do with our hands. As Hutchins shows so beautifully, in his Cognition in the Wild, our cognition is a distributed process in which humans and artifacts together create calculation and intelligent performance. So rather than confusing vocabulary with thinking, as you seem to do when you ask us to keep our thinking open by keeping our vocabularies open, I would much rather have us think about thinking as something we make with artifacts, handwork, physical motion, tactile manipulation, inscriptions, and, of course, words as well. We make ideas, systems, and minds as we work with objects and words-we don't have understandings first and then merely put them in words. We should focus then on the making of cognition in as open a way as possible, not the blending of voices as if they were ready made. Think, Richard, of how you treat language as a ready made "thing" for workers to pick up and use. When you ask us to search for new languages or vocabularies, you ask us to "cast about" for them as if we could just fish a new vocabulary out of a stream.

To pick up on the tool metaphor you started to develop but then dropped, I would like us to think of system work as tool based work. The tools that they use in doing system work are their language, and the kinds of tools they are able to put to hand are their vocabularies. It is not just the words they use, but all the diagram techniques, interviewing strategies, and the ways they use their bodies and their hands that are the thinking and the language of system work. Maybe if we could see a kind of continuous motion picture of the system worker close up, it would help us see how unique and singular each site of system work is. If there are limits to this hand-work language, they are to be found in each filming location where the actors are using both words and artifacts in making their own contexts as they make the organization and its information systems. So there are only local limits, and local limits will prevail in language use.

Pierre Bourdieu: Well, perhaps there are local limits, but this is only true in a trivial sense, a sense in which the langue and parole of language are confused. The local, 
situated use of langue, its parole, will always be a limit in a superficial sense. Of course, in understanding the logic of social practice, they are profoundly important, but in a generative sense, which seems to be the focus here, the structuring structure of language, its langue, is the determining language operation. Langue and the structure of its binary oppositions set the limits of language that will prevail in doing system work.

West Churchman: I feel that in my saying what I conclude about language, I have ended up being mischaracterized here, and perhaps at some later time that is a part of the limits of language that I will think about further. But for now, what I must point out is how my conclusions about reason, guarantors, and the need for a sense of the whole system have turned out to mask something even more important in my views on language and their limits-something that serves as my ontological grounding and is in stark contrast to Bourdieu and Latour. Reason, guarantors, or a sense of whole are not the wellspring of my thinking - they are merely the best conclusion I can reach, using both logic and emotion. The wellspring for my thinking is the individual human being. The lonely, isolated, mortal, struggling, flesh and blood human being who acts: that is what requires reason, sense of whole, and a guarantor. And that foundation of the singular, passionate, morally responsible, and often anguished human from which I draw my conclusions is missing from all these arguments.

I am a humanist, pure and simple, and I am proud of it. I reject what both Latour and Bourdieu have said-realizing that they disagree between themselves quite strongly, but seeing each of them as losing sight of the primacy of the individual. Latour accuses me of looking to the imaginary and the unknowable for the operation of reason. But he, in turn, has made the individual disappear in favor of a circulating network in which artifacts are as important as humans, any node of which is subject to the same types of mediation and translations of interests. Bourdieu makes the individual disappear into recursively reproduced practices where habits replace the passion and will of the singularly potent person. Give me the flesh and blood, the agonizing existential reality of the human being facing the dread of everyday responsibilities. That's where I want to start. That is what is real: the individual human actor answering to God and the future of humankind for her actions.

Richard Rorty: That's good, very good - a nice dramatic move, West. It really got me on my feet and dancing and that's important after so much solemn celebration of the cerebral. Seriously, though, what you say is important because it brings us back to the way that our existence in a human community activates our emotions, our sense of affiliation, our sense of moral responsibility, and all the many uniquely human qualities that should, I think, be central to this discussion of language and limits. It seems to me that West's passion for the morally responsible individual is important if we are to bring ourselves as human actors and our own limits into this discussion, which I think we must. Literature, of course, is another way to do that.

Geoffrey Vickers: Your own writing has prompted me to reread Wittgenstein and I must say he seems to be very central to what West Churchman is saying about the flesh and blood person. But I'm not sure he comes to the same conclusion, if it could be said that he comes to any conclusion at all. Wittgenstein's own search for the ideal 
in language and for logic as a guarantor of the truth of our statements seems to be the place Churchman is ending up, with both of them having become aware of the limits of logical propositions and reasoning. But Wittgenstein later abandoned that search for logic and embraced the importance of language use in forms of life, or as he called them, language games. He warned us against letting our language "go on holiday" as it does in most theorizing, losing touch with the "rough ground" of engagement in the world. Rather than searching for a guarantor, making a careful description of the actual use of language in its multiplicity of possible meanings is all we can hope to achieve. There is no higher question about language. Appeals to theory are, therefore, irrelevant.

Bruno Latour: Finally, something I can agree with. You cannot get too close or too detailed in your description of social life or organizational work. And maybe that is the curse of system development. It is, of necessity, a search for the abstract and the general in the face of the details of life as it unfolds. If system designers could abandon their models and keep their noses closer to the ground, we would all be better off.

Geoffrey Vickers: I see we are running out of time here. We seem to have covered a lot of ground in our discussions, but I'm wondering just how far we have really come. I have told the Millennium Technology Committee that we would prepare some kind of statement summarizing our position on the limits of language in doing system work, and I do hope we can achieve that; perhaps in a subsequent session.

Richard Rorty: Yes, I see we have about one minute left, enough for me to make a final point. I have enjoyed Bruno trying to find a weak spot-or should I say a strong spot - in my ontology of language. But I think it's safe to say that I can match him or anyone step for step in following a Wittgensteinian path of appreciating that "knowing how to go on" is about all we can hope for when it comes to theorizing organizational work. Let me close, though, by pointing out the one limit no one has made clear, and that is the limit of being in language and at the same time trying to talk about language and its limits. Bruno thinks my metaphor of casting about for new vocabularies is ontologically misguided, but at least I don't presume we can somehow step outside of language. Whether you hope for a rational guarantor, a careful description, a reflexively cleansed approach to studying fields of practice, or a greater control over language construction and language choice, you are relying on a rather amazing capacity to use language to observe language as if from afar. I don't hold any such pretension and I am skeptical of any claims that rely on such an ability.

Geoffrey Vickers: I'm going to have to let that be the last word in this conversation. I think it's safe to say that many interesting and challenging ideas have come out of this roundtable. I'm not surprised we couldn't reach some agreement in such a short time, but I am hopeful that the conversation we have started can be continued by us and by others who are as fascinated by language and language use as I am. Thank you for participating. 


\section{Acknowledgments}

The author appreciates the constructive criticism made by Geof Bowker and Ulrike Schultze on an earlier version of this paper, and the helpful discussion she had with Barbara Czarniawska while it was being written.

\section{References}

Bourdieu, P. Outline of a Theory of Practice. Cambridge, UK: Cambridge University Press, 1997.

Bourdieu, P. The Logic of Practice. Stanford: Stanford University Press, 1990.

Bourdieu, P., and Wacquant, L. J. D. An Invitation to Reflexive Sociology. Chicago: University of Chicago Press, 1992.

Churchman, C. W. The Design of Inquiring Systems: Basic Concepts of Systems and Organization. New York: Basic Books, 1971.

Churchman, C. W. The Systems Approach. New York: Delacorte Press, 1968.

Churchman, C. West. 1968. The Challenge to Reason. New York: McGraw-Hill

Latour, B. Science in Action. Cambridge, MA: Harvard University Press, 1987.

Latour, B. Aramis or the Love of Technology. Cambridge, MA: Harvard University Press, 1986. Latour, B. We Have Never Been Modern. Cambridge, MA: Harvard University Press, 1993.

Rorty, R. Philosophy and the Mirror of Nature. Princeton, NJ: Princeton University Press, 1979.

Rorty, R. Consequences of Pragmatism. Minneapolis, MN: University of Minnesota Press, 1982

Rorty, R. Contingency, Irony, and Solidarity. Cambridge, England: Cambridge University Press, 1989.

Vickers, G. Value Systems and Social Process. Harmondsworth, UK: Penguin Books, 1970.

Vickers, G. The Art of Judgement. New York: Basic Books, 1965.

Vickers, G. Freedom in a Rocking Boat. Harmondsworth, UK: Penguin Books, 1970.

\section{About the Author}

Richard J. Boland, Jr. is Professor and Chair of the Department of Information Systems at the Weatherhead School of Management at Case Western Reserve University. Previously he was Professor of Accountancy at the University of Illinois at UrbanaChampaign. He has held a number of visiting positions, including the Eric Malmsten Professorship at the University of Gothenburg in Sweden in 1988-89, and the Arthur Andersen Distinguished Visiting Fellow at the Judge Institute of Management Studies at the University of Cambridge in 1995. His major area of research is the qualitative study of the design and use of information systems. Recent papers have concerned sense making in distributed cognition, hermeneutics applied to organizational texts, and narrative as a mode of cognition. Richard is Editor-in-Chief of the research journal Accounting, Management and Information Technologies, and co-editor of the Wiley Series in Information Systems. He serves on the editorial board of six journals, including Information Systems Research and Accounting, Organizations and Society. He can be reached by e-mail at rjb7@po.cwru.edu. 